\title{
Effect of moringa and bagasse ash filler particles on basalt/epoxy composites
}

\author{
Prakash Sampath ${ }^{1}$ (D) and Senthil Kumar Velukkudi Santhanam ${ }^{1 *}$ (D) \\ 'Department of Mechanical Engineering, Anna University, Chennai, Tamil Nadu, India \\ *vssk70@gmail.com
}

\begin{abstract}
This study evaluated the effect of moringa and nano ash filler particles on mechanical, chemical corrosion and moisture absorption of basalt fiber/epoxy composites. Epoxy resin and Araldite HY951 hardener was used as matrix along with the inclusion of filler particles while the bi-directional woven basalt fiber mat was used as the reinforcement in fabricating composites using hand layup technique. Three different composites i.e. Plain BF + matrix with no filler particles, BF + matrix with $10 \mathrm{wt}, \%$ moringa ash and $\mathrm{BF}+$ matrix with $10 \mathrm{wt}, \%$ bagasse ash were fabricated and tested according to the ASTM standards to determine the mechanical properties and chemical corrosion resistance. According to the experimental test results, the composites with moringa ash inclusion showed better properties than the bagasse ash inclusion and with no filler added composites.
\end{abstract}

Keywords: bagasse ash, basalt fiber, chemical corrosion, Moringa ash.

How to cite: Sampath, P., \& Santhanam, S. K. V. (2019). Effect of moringa and bagasse ash filler particles on basalt/epoxy composites. Polimeros: Ciência e Tecnologia, 29(3), e2019034. https://doi.org/10.1590/0104-1428.01219

\section{Introduction}

Basalt fiber based polymer composites play a major role in the automobile and aircraft industries and are seen as better substitutes for glass and carbon fiber with advantages in terms of cost, eco-friendly, seawater resistance, sufficient interfacial adhesion, resistance to chemical and better mechanical properties. Basalt fiber composites have found extensive applications in fuselage, wind turbine blades, pipelines in petrochemical industries, a fine line of front car bumpers, and ship body etc. ${ }^{[1-4]}$. Natural filler particle's have become alternative reinforcing in various areas of polymer matrix composites due to their advantages over synthetic fibers, e.g. low density, less tool wear during processing, low cost, non-toxic, easy process, environmentally friendly, and biodegradability ${ }^{[5]}$.

The determination of carbonized bone charcoal particles used in the polypropylene composite enhanced the resistance of the material to surface damage ${ }^{[6]}$. The Basalt/epoxy composites had improved young's modulus and impact behaviour in comparison with the Glass/epoxy composites ${ }^{[7-9]}$. The composite strength by coating of nano- sio $_{2}$ on basalt fiber was improved interface bonding resistance ${ }^{[10]}$.

The agriculture-plant waste, prepared as bio organic particles, is currently the best suitable, inexpensive and eco-friendly material for the fabrication of advanced composite materials. Many researchers have reported the use of bagasse, dust, rice husk, nano fly ash and coconut shells as filler materials in fabricating polymer composites ${ }^{[11-16]}$, in nature mineral fillers were added in the resin and applied on the fiber, showed increase in the mechanical behavior ${ }^{[17,18]}$. The determination of Sugarcane bagasse in the form of ash particles and suggested that it be used as fillers in cement and clay bricks, due to its being rich in crystalline silica ${ }^{[19]}$. The experimental on rigid $\left(\mathrm{Al}_{2} \mathrm{O}_{3}\right)$ as nano filler in a glass fiber composite found that the mechanical properties improved up to (5-10) $\mathrm{wt} \%$ filler content ratio in a glass fiber composite ${ }^{[20]}$.

Many investigations on oil palm ash's (OPA) have rigid nano filler content in the unsaturated polyester polymer matrix with $5 \mathrm{wt} \%$ to $35 \mathrm{vol} \%$ filler content ratios, and observed that the mechanical properties were improved ${ }^{[21]}$. In nature the latent of maize stalk charcoal particles as reinforced in polyester composites enhanced the tensile properties of composites ${ }^{[22]}$.

In most situations, fiber reinforced composites are widely used in automobile components and aircraft structure applications: therefore testing a polymer matrix composite after creation a drilled hole develops unavoidable. The big size of an open hole leads to high stress absorption in the open hole composite. The open hole tensile (OHT) strength of maleic anhydride mixed polypropylene (MAPP) dried polymer matrix composites had increased their tensile properties by $4-7 \%{ }^{[23]}$. Investigated the tensile and impact performance of coal ash strengthened (at various wt \%) glass fiber composites and then concluded. The $20 \%$ and $16 \%$ of coal ash strengthened glass fabric laminates exhibits better performance during tensile and impact tests than compared to other $(0 \%, 4 \%, 8 \%$ and $12 \%$ wt coal ash) composite laminates ${ }^{[24]}$.

An investigation on Chemical corrosion on the polymer matrix composites is necessary in some 
applications. For example, some containers, off-shore, vessels, tubes, platforms and equipment's in marine and chemical industrial applications may be corroded after long-term service in an alkali environment. It is supposed that one of the difficulties precluding the extensive use of polymer composites is the lack of long-term durability and performance data when servicing in critical environments. So, it is necessary to understand how the materials behave during chemical corrosion on long-term applications ${ }^{[25,26]}$.

The determination of $\mathrm{HNO}_{3}$ exhibited the stronger corrosion to ECR glass fiber than that in different $\mathrm{HCl}$ and $\mathrm{H}_{2} \mathrm{SO}_{4}$. For $\mathrm{HCl}$, it mainly destroys the network structure of $\left[\mathrm{AlO}_{4}\right]$, while $\mathrm{H}_{2} \mathrm{SO}_{4}$ and $\mathrm{HNO}_{3}$ destroy the structure of $\left[\mathrm{SiO}_{4}\right]$. Moreover, the sizing effect on acid resistance of ECR glass fiber is also discussed here. The sizing agent has limited protection time about $70 \mathrm{~h}$ on glass fiber ${ }^{[27]}$. The determination of no natural filler fibres have very low water absorption followed by samples with chemically treated natural fiber and untreated natural fiber exhibit maximum water absorption. Specimens with chemically treated fibres exhibit lower water absorption than specimens fabricated using untreated fiber as a result of surface of natural fiber getting modified by alkaline treatment which aids in good interface bonding between matrix and fiber. The specimen reinforced with banana fiber exhibit increased water absorption as the volume of banana fiber in the composite is more than that of bagasse ${ }^{[28]}$.

To the best of author's knowledge, no scientific report was made to investigate the effect of MOA ash particles as filler particles in the basalt fiber reinforced polymer composites. Only a few researchers have focused on natural filler particles influence on the polymer composites. The goal of this research was to investigate the usage of agro waste ash particles as fillers in basalt/epoxy composites. Furthermore, the effects of moringa and bagasse ash filler particles on the chemical composition, mechanical, chemical corrosion and water absorption properties of fabricated composites have determined.

\section{Materials and Methods}

\subsection{Materials}

Bagasse waste was collected from sugarcane industry and Moringa from green farm house. Chemicals used were hydrochloric acid, sodium hydroxide and ethanol. Basalt fiber in the form of bi-directional woven mat was applied as the reinforcement with a matrix mixture (LY556 Epoxy resin + Hardener) in the ratio of 1:10. The Moringa and bagasse were chemically treated by submerging the strands in $\mathrm{NaOH}$ solution for $6 \mathrm{hr}$ at room temperature and dried. Strands were converted into powder using a mill grinder. Bagasse and Moringa oleifera were heated using an electric furnace at a temperature of $500{ }^{\circ} \mathrm{C}$ for $5 \mathrm{hr}$ to obtain ash. Ash particles were mixed with $2.5 \mathrm{~mL} \mathrm{NaOH}$ solution, boiled at $75^{\circ} \mathrm{C}$ for $3 \mathrm{hr}$ with magnetic stirrer. The precipitate was mixed with distilled water and filtered. The process was continued 3-4 times for the deletion of $\mathrm{NaOH}$ solution from ash. The resultant was filtered, mixed with $2 \% \mathrm{HCl}$ solution and boiled at $75^{\circ} \mathrm{C}$ for $4 \mathrm{hr}$. The collected precipitate was finally filtered, mixed with $1 \%$ ethanol and dried at $110{ }^{\circ} \mathrm{C}$ for $10 \mathrm{hr}$ in an oven. Table 1 shows the chemical composition of moringa and bagasse ash particles.

\subsection{Method}

Hand lay-up method was used for the composite fabrication process. Addition of 10 gms of natural fillers Moringa and Bagasse was mixed in $200 \mathrm{ml}$ of epoxy resin and mechanically stirred for $15 \mathrm{~min} .100 \mathrm{~mL}$ hardener was added in the resin and stirred for $30 \mathrm{~min}$. The resin/hardner mixture was taken in the ratio of 2:1 to obtain a curing time of $3 \mathrm{hr}$. A layer of basalt fiber mat was spread over the mould and resin mixture was introduced over the surface of the fiber mat. The resin evenly spread all over the matrix using a roller. This procedure was repeated for 8 fiber laminas to obtained at specimen thickness of $3.5 \mathrm{~mm}$. Table 2 shows the fabricated composite/specimen notations used.

Water absorption test was conducted on composites of dimensions $3 \times 3 \times 3 \mathrm{~mm}$. The composite samples were fully immersed in a beaker containing distilled water maintained at atmospheric temperature and then removed at periodic intervals. The water on the specimen surface was removed and was weighed immediately. The water absorption percentage is calculated using the Equation 1.

$$
\Delta \mathrm{W} \%=\frac{\mathrm{W}_{\mathrm{t}-} \mathrm{W}_{\mathrm{d}}}{\mathrm{W}_{\mathrm{d}}}
$$

where, $\mathrm{W}_{\mathrm{t}}$ - weight of wet composite, $\mathrm{W}_{\mathrm{d}}$ - weight of dry composite

Fabricated composites were cut into small pieces weighing 5-10 gm and immersed in $150 \mathrm{~mL}$ acid solution for varying time durations from 24 to $120 \mathrm{hr}$ at room temperature. The three different acid solutions are sulfuric acid, nitric acid and hydrochloric acid. The corroded composite samples

Table 1. Chemical composition of moringa and bagasse ash particles.

\begin{tabular}{ccc}
\hline \multirow{2}{*}{ Elements } & $\begin{array}{c}\text { \% composition } \\
\text { Moringa }\end{array}$ & \% composition \\
\cline { 3 - 3 } & 67.22 & Bagasse \\
\hline $\mathrm{SiO}_{2}$ & 2.4 & 65.4 \\
$\mathrm{Al}_{2} \mathrm{O}_{3}$ & 7.45 & 1.92 \\
$\mathrm{Fe}_{2} \mathrm{O}_{3}$ & 1.9 & 7.36 \\
$\mathrm{TiO}_{2}$ & 0.87 & 1.46 \\
$\mathrm{P}_{2} \mathrm{O}_{5}$ & 5.35 & 0.98 \\
$\mathrm{CaO}$ & 1.24 & 5.0 \\
$\mathrm{MgO}$ & 0.91 & 1.17 \\
$\mathrm{Na}_{2} \mathrm{O}$ & 7.07 & 0.87 \\
$\mathrm{~K}_{2} \mathrm{O}$ & 0.64 & 6.22 \\
$\mathrm{SO}_{3}$ & & 0.42 \\
\hline
\end{tabular}

Table 2. Specimen notation for fabricated composites and respective matrix fraction.

\begin{tabular}{|c|c|c|c|c|}
\hline $\begin{array}{l}\text { SI. } \\
\text { No. }\end{array}$ & $\begin{array}{l}\text { Composite/ } \\
\text { specimen }\end{array}$ & $\begin{array}{l}\text { Hardener } \\
\quad(\mathrm{mL})\end{array}$ & $\begin{array}{c}\text { Epoxy Resin } \\
\text { (mL) }\end{array}$ & $\begin{array}{l}\text { Ash filler } \\
\text { particles } \\
10 \text { wt. \% }\end{array}$ \\
\hline 1 & A & 100 & 200 & - \\
\hline 2 & B & 100 & 200 & Bagasse \\
\hline 3 & $\mathrm{C}$ & 100 & 200 & Moringa \\
\hline
\end{tabular}


were sanitized with the help of distilled water, and dried in oven. Further the weight loss of acidic treated composites was measured using an electronic weigh balance with an accuracy of $0.0001 \mathrm{gm}$. The weight loss ratio was calculated using Equation 2.

$$
\mathrm{W} \%=\frac{\mathrm{M}_{0-} \mathrm{M}_{1}}{\mathrm{M}_{1}}
$$

where, $\mathrm{M}_{0}-$ Initial mass of composite, $\mathrm{M}_{1}-$ Final mass after acid treated

The impact (charpy) test specimens with dimensions $75 \times 10 \times 10 \mathrm{~mm}$ having a groove penetration of $1.5 \mathrm{~mm}$ and a groove point radius of $0.02 \mathrm{~mm}$ at an angle of $45^{\circ}$ was used. The tensile test specimens with dimensions $165 \mathrm{~mm} \times 19 \mathrm{~mm}$ (dog bone shape) were prepared according to the ASTM D638 standard.

\section{Results and Discussions}

\subsection{Open hole tensile test}

Open hole tensile tests were carried out using a universal testing machine (make: INSTRON $50 \mathrm{KN}$ ) and the results are shown in Table 3. From Figure 1 it is evident that the composite $\mathrm{C}$ has higher tensile strength compared to the other composites. The composite A exhibited 30\% lesser tensile strength than the ash filler particles included composites. The addition of ash filler particles enhances the matrix adhesion strength and increases interfacial bond strength between matrix and fiber. The chemical treatment of ash filler particles removed the impurities by neutralizing the potential of hydrogen i.e. acid and base treatment and this helps in improved wettability with the matrix and increases the elastic behaviour of the matrix. The ash filler particles

Table 3. Open hole tensile test results.

\begin{tabular}{cccccc}
\hline S.no & $\begin{array}{c}\text { Composite/ } \\
\text { specimen }\end{array}$ & Load, kN & $\begin{array}{c}\text { Displacement, } \\
\mathbf{m m}\end{array}$ & $\begin{array}{c}\text { Stress, } \\
\mathbf{M P a}\end{array}$ & $\begin{array}{c}\text { Elongation } \\
\mathbf{\%}\end{array}$ \\
\hline 1 & $\mathrm{~A}$ & 5.78 & 4.15 & 84.7 & 2.12 \\
2 & $\mathrm{~B}$ & 7.27 & 5.01 & 113.39 & 2.56 \\
3 & $\mathrm{C}$ & 8.51 & 5.20 & 138.6 & 2.66 \\
\hline
\end{tabular}

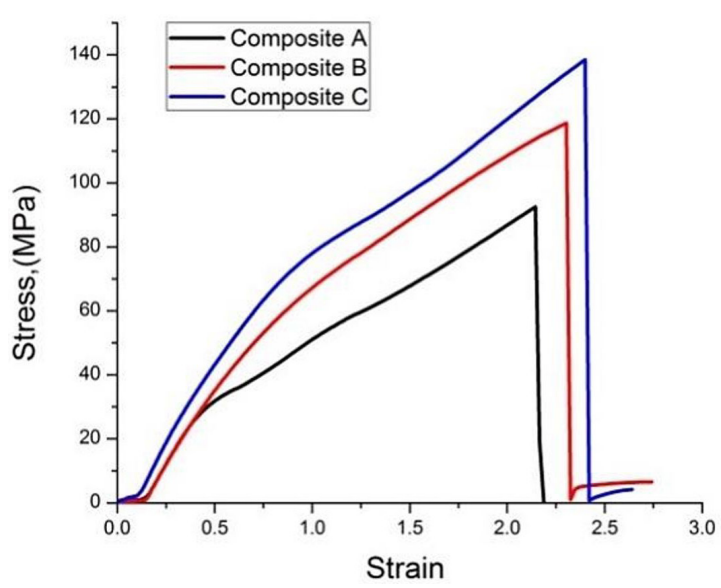

Figure 1. Stress vs strain plot for open hole tensile test of fabricated composites. have a globular structure and provide more surface contact area with the matrix increasing bond strength.

The presence of silica in Moringa ash contributes to the increase in tensile strength and this result agrees well with the results of $\mathrm{Bin}$ wei ${ }^{[29]}$ that the $\mathrm{SiO}_{2}$ nano-filler increased the bonding rigidity of basalt fiber/epoxy composite. Figure 1 shows the stress-strain plot which clearly reveals that composite $\mathrm{C}$ had higher stress values and elongation $\%$ compared to Composite A and composite B. The matrix failure in the composite A occurred in early stage due to the poor wettability with the fiber. Composite A suffered failure at $84.7 \mathrm{MPa}$ due to disintegration of matrix and fiber interface. Composite B and C showed improved strength due to better bonding between the matrix and fiber which consequently resulted in increased interfacial shear strength. The composite $\mathrm{C}$ had higher elastic limit due to the presence of Moringa ash particles in the matrix increasing it yield strength. This is because as the filler content increased, the interfacial bonding area also increased between the filler (hydrophilic) and the epoxy matrix (hydrophobic), which increases the tensile strength ${ }^{[30-32]}$.

\subsection{Impact test}

Figure 2, shows the total energy absorbed by the composite specimen $\mathrm{A}, \mathrm{B}$ and $\mathrm{C}$ during the impact test and the results are shown in Table 4. Composite $\mathrm{C}$ had an energy absorption of $24 \mathrm{~J}$ and this was $16 \%$ higher than the composite B (20.6 J) and $47 \%$ higher than composite $\mathrm{A}(16.3 \mathrm{~J})$.

The higher percentage of silica particles present in moringa ash filler particles in the composite $\mathrm{C}$ improved the fracture toughness of composites compared to composite B as shown in Figure 2. The same results have found that the uniform distribution of the ash filler particles led to the improvement in fiber-matrix adhesion properties as the existence of rigid fillers particles reduced the matrix brittle behaviour. The similar result have found with the impact performance of $20 \%$ and $16 \%$ of coal ash filled glass fiber composite exhibits better performance during the impact test than compared to other $(0 \%, 4 \%, 8 \%$ and $12 \%$ wt coal ash) composite laminates ${ }^{[24]}$.

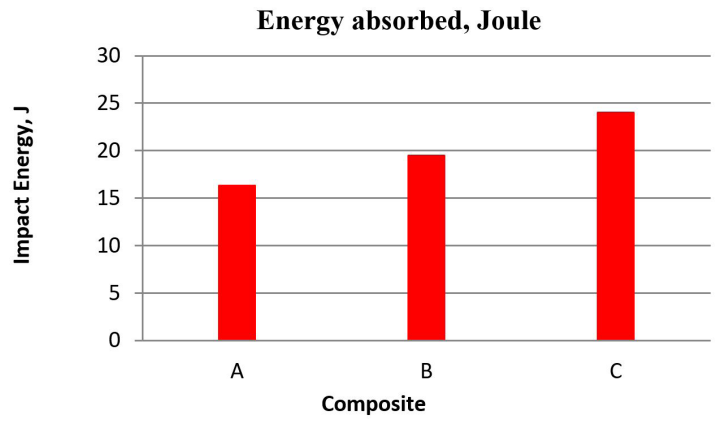

Figure 2. Impact test results.

Table 4. Energy Absorption of specimen.

\begin{tabular}{ccc}
\hline S.NO & Composite/Specimen & Energy Absorption, Joules \\
\hline 1 & $\mathrm{~A}$ & 16.3 \\
2 & $\mathrm{~B}$ & 20.6 \\
3 & $\mathrm{C}$ & 24 \\
\hline
\end{tabular}




\subsection{Chemical corrosion}

From Figure 3. Corrosion test specimens immersed in three different acid solutions and Table 5 shows the weight loss calculation of each composite specimen using sulphuric acid, nitric acid, hydrochloric acid. Deterioration in composite A was found to be higher when compared to other composites when treated in sulphuric acid. The Sulphuric acid caused weight losses by destroying the network structure of $\mathrm{SiO}_{4}$ present in filler particles and fibers. The weight loss of composite $\mathrm{A}$ is due to chemical reaction of matrix with the acid solution. From Figure 4, it is observed that the weight loss $\%$ increases with increasing time duration. For the composites $\mathrm{B}$ and $\mathrm{C}$ with the inclusion of filler particles, the composites underwent observable changes beyond the $90 \mathrm{hr}$ as the acidic resistance is limited.

The composite A shows linear increase in wt. \% loss beyond $90 \mathrm{hr}$. Composites treated in sulphuric acid vs weight loss is shown in Figure 4, for nitric acid in Figure 5 and for hydrochloric acid in Figure 6. The results showed that ion precipitation rate of composite $\mathrm{A}$ are lesser than that of composite B and C. The rigid filler particles on the basalt/epoxy composite can reduce the acid corrosion, which leads to the low weight loss rate in the initial stage of

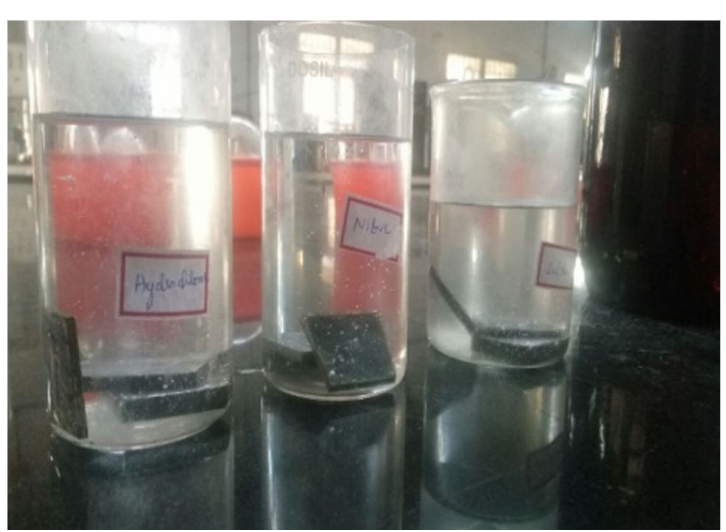

Figure 3. Corrosion test - specimen immersed in acid solution. corrosion. When the chemical reaction between epoxy and acid occurs, the protective effect on basalt fiber weakens. Therefore, the ash filler particles act a barrier in limiting the corrosion of epoxy matrix in all the acid solutions considered. The similar results were found from the glass fiber composite with three acid solutions Therefore, basalt fiber composites has high acid resistance compare than ECR glass fiber and has been used in the manufacture of basalt fiber reinforced plastic pipeline ${ }^{[27-31]}$.

\subsection{Water absorption}

Basalt fiber contains plenty of hydroxyl groups which react with water molecules and form hydrogen bonds. The water molecules easily penetrate in the composite A due to weak bonding of the matrix and basalt fiber.

The chemically treated filler particles have better interfacial bond strength with the matrix and the fiber which reduced the penetration of water molecules to react with the fiber. From Table 6 the composite $\mathrm{C}$ has improved the water absorption capacity. The water absorption results are shown in Figure 7. The similar results have found from the water absorption of the composites increases at higher filler particles content, although there was not much difference

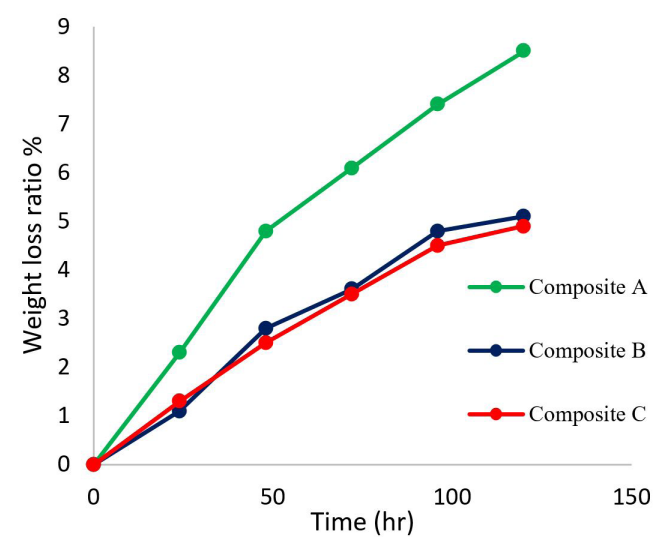

Figure 4. Weight loss ratio of Sulphuric acid treated samples.

Table 5. Weight loss test result of different composite into different acid solutions.

\begin{tabular}{|c|c|c|c|c|c|}
\hline \multirow{2}{*}{ S.NO } & \multirow{2}{*}{ Composite } & \multirow{2}{*}{ Time (hr) } & $\mathrm{H}_{2} \mathrm{SO}_{4}$ & $\mathrm{HNO}_{3}$ & HCL \\
\hline & & & Mass loss, wt \% & Mass loss, wt \% & Mass loss, wt \% \\
\hline \multirow[t]{5}{*}{1} & A & 24 & 2.3 & 2 & 3 \\
\hline & & 48 & 4.8 & 4.6 & 5.29 \\
\hline & & 72 & 6.09 & 6 & 6.2 \\
\hline & & 96 & 7.4 & 6.7 & 6.3 \\
\hline & & 120 & 8.5 & 7.9 & 8.6 \\
\hline \multirow[t]{5}{*}{2} & B & 24 & 1.1 & 1.48 & 0.72 \\
\hline & & 48 & 2.8 & 3 & 1.8 \\
\hline & & 72 & 3.6 & 3.79 & 2.7 \\
\hline & & 96 & 4.8 & 4.8 & 4.3 \\
\hline & & 120 & 5.1 & 5.25 & 4.5 \\
\hline \multirow[t]{5}{*}{3} & $\mathrm{C}$ & 24 & 1.3 & 1.37 & 0.58 \\
\hline & & 48 & 2.5 & 3.2 & 2.19 \\
\hline & & 72 & 3.5 & 3.8 & 2.4 \\
\hline & & 96 & 4.5 & 5 & 3.2 \\
\hline & & 120 & 4.9 & 5.29 & 4.7 \\
\hline
\end{tabular}




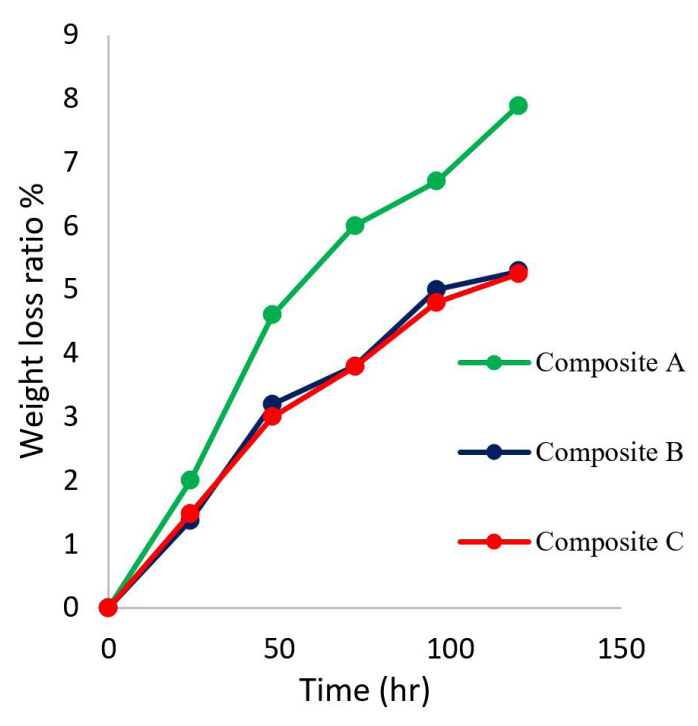

Figure 5. Weight loss ratio of Nitric acid treated samples.

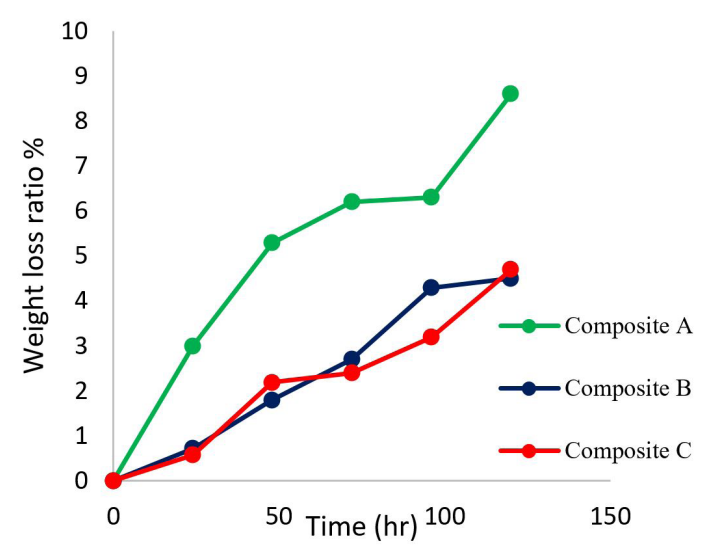

Figure 6. Weight loss ratio of hydrochloric acid treated samples.

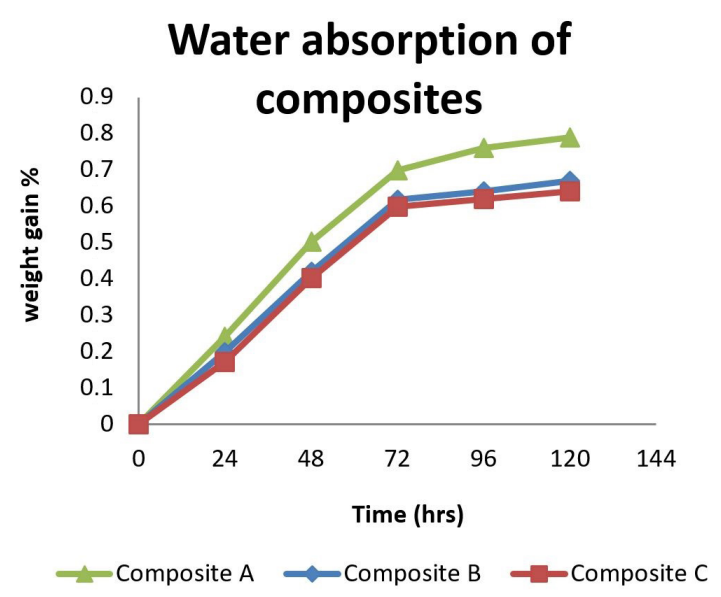

Figure 7. Water absorption result.
Table 6. Calculation of water absorption ratio by different composites.

\begin{tabular}{cccccc}
\hline \multirow{2}{*}{ Composite } & \multicolumn{5}{c}{$\Delta \mathbf{W} \%$} \\
\cline { 2 - 6 } & $\mathbf{2 4 h r s}$ & $\mathbf{4 8 h r s}$ & $\mathbf{7 2 h r s}$ & $\mathbf{9 6 h r s}$ & $\mathbf{1 2 0 h r s}$ \\
\hline A & 0.24 & 0.502 & 0.698 & 0.76 & 0.79 \\
B & 0.171 & 0.402 & 0.598 & 0.62 & 0.64 \\
C & 0.197 & 0.419 & 0.617 & 0.64 & 0.67 \\
\hline
\end{tabular}

in water absorption between composites with banana filled basalt fiber composite have exhibit increases water absorption as the volume of banana fiber in the composite is more than that of bagasse filled composites ${ }^{[28]}$.

\subsection{Failure analysis using SEM}

From SEM images, the following failures were identified: (a) fiber crack, (b) crack propagation, (c) fiber debonding, (d) matrix crack and fiber breakage, (e) fiber pullout, (f) porosity, (g) Matrix crack and fiber failure, (h) Fiber breakage and fiber crack. From Mechanical properties (Open hole tensile and Impact test) test result, the material absorbs the energy through plastic deformation, and it could be observed from the formation of surface crack by failure mechanism.

Figure 8 (a-d) Shows that with the addition of natural filler in the basalt fiber composite exhibited improved mechanical properties as observed in the fiber failure in the depressed zone when compared to the plain basalt fiber composite. Intra layer failures and matrix cracking have been identified from the SEM images.

Figure 8 (e-j) Indicates the morphological feature of natural fillers reinforced basalt fiber composite immersed into the three different acid solutions as examined using scanning electron microscopy (SEM). The agglomeration of particles, resulting in poor interfacial bonding between the particle-fiber-epoxy interactions created different modes of failure on the basalt fiber composite laminates. SEM images provide a better explanation of the damage modes of composites like matrix breakage, fiber breakage, delamination, etc. Presence of Moringa ash filler particles on the surface of basalt and in the epoxy matrix confirms the homogeneous distrubtion of ash particles. This is a qualitative indication of a greater interfacial strength between the fiber-filler and the matrix-filler.

Figure $8(\mathrm{k}-1)$ Shows the SEM images of composite surface after the water absorption test. If voids content is higher in the natural fillers reinforced basalt fiber composite, there is a more chance for higher amount of water absorption and if voids are less, the composite absorb less amount of water in the particle-fiber-epoxy system. Higher void content in the composites causes degradation of composites due to higher absorption and also creates poor interfacial bonding between the natural filler in the epoxy and the matrix. The effect would degrade the composite strength. Water absorption of moringa filler reinforced basalt fiber composite is less than that of bagasse filler reinforced composite due to minimum voids in the moringa filled composites. 

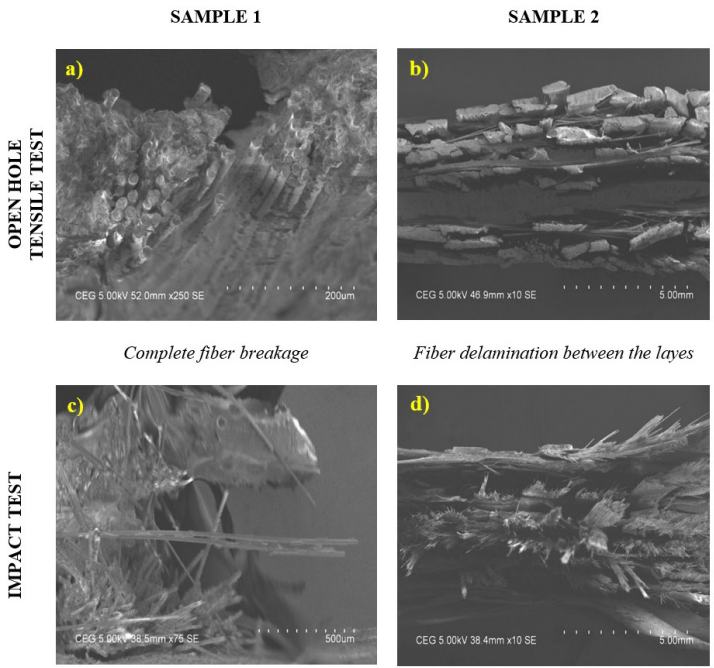

Fiber delamination between the layes

Fiber dislocation

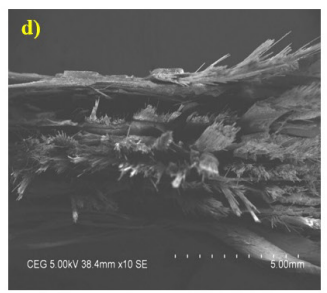

Matrix delamination, and fiber crack initiation
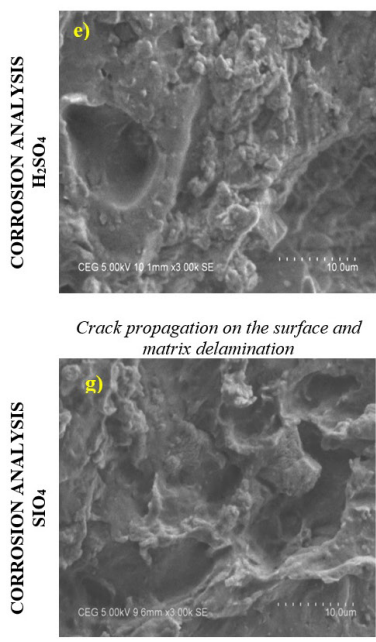

Surface Fracture and Fiber failure

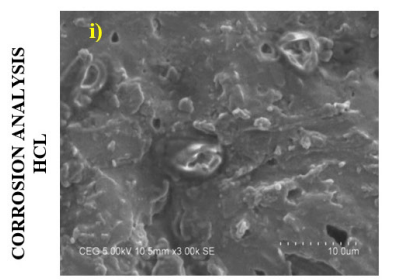

Extension of Matrix crack and fiber failure

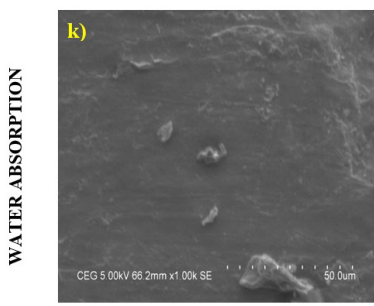

Fiber surface failure

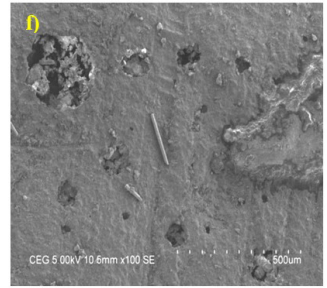

Surface crack and dent initiation and

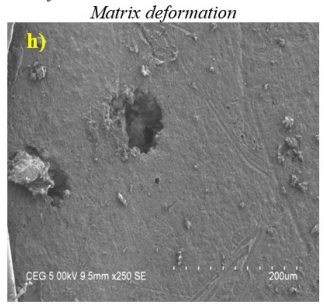

Plastic deformation and Surface Fracture

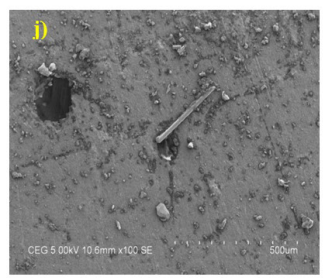

Fiber breakage and fiber crack

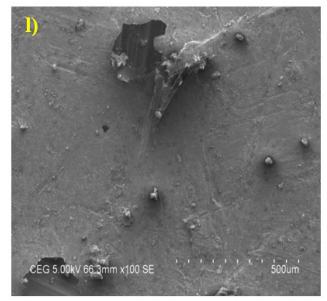

Crack propagation on the surface and matrix delamination

Figure 8. Microstructural image for Tested composites (a-1).

\section{Conclusions}

The composite materials were successfully fabricated using hand lay-up technique with basalt fiber as the reinforcement and inclusion of fillers (moringa and bagasse ash particles) as the matrix. From the experimental study, the following conclusions have been drawn:

- Open hole tensile strength of the composites $\mathrm{C}$ had higher ultimate strength (138.6 MPa) which is $17 \%$ higher than composite B (113.39 MPa) and $47 \%$ of composite $\mathrm{A}(84.7 \mathrm{MPa})$ and this was due to the presence of ash filler particles in strengthening the matrix yield strength.

- The impact strength of the composite $\mathrm{C}$ was $16 \%$ higher than composite B and $47 \%$ of composite A due to the strengthening effect of silica particles present in the moringa ash.

- The resistance to chemical corrosion was higher in the composites B \& C with the inclusion of ash filler particles when treated under sulphuric acid, nitric acid, hydrochloric acid solutions.

- The water absorption of the composite $\mathrm{C}$ exhibited the better resistance than that of composite $\mathrm{B}$ and $\mathrm{A}$ due to the increase in interfacial bond resistance between the matrix and the fiber.

- The microstructural analysis of SEM image suggested that the fractured surfaces, internal cracks and interfacial properties are observed the tested composite.

\section{Acknowledgements}

The authors gratefully acknowledge the assistance from Department of Science and Technology, New Delhi in the financial support to carry out this research work under Promotion of University Research and Scientific Excellence - II scheme. One of the authors, Mr. Prakash Sampath is thankful to Department of Science and Technology, New Delhi for the award of Department of Science and Technology - Promotion of University Research and Scientific Excellence fellowship.

\section{References}

1. Bissoli-Dalvi, M., Nico-Rodrigues, E. A., Alvarez, C. E., Fuica, G. E. S., \& Montarroyos, D. C. G. (2016). The sustainability of the materials under the approach of ISMAS. Construction \& Building Materials, 106, 357-363. http://dx.doi.org/10.1016/j. conbuildmat.2015.12.030.

2. Saba, N., Paridah, M. T., \& Jawaid, M. (2015). Mechanical properties of kenaf fibre reinforced polymer composite: a review. Construction \& Building Materials, 76, 87-96. http:// dx.doi.org/10.1016/j.conbuildmat.2014.11.043.

3. Balakrishnan, H., Hassan, A., Wahit, M. U., Yussuf, A. A., \& Razak, S. B. A. (2010). Novel toughened polylactic acid nanocomposite: mechanical, thermal and morphological properties. Materials \& Design, 31(7), 3289-3298. http:// dx.doi.org/10.1016/j.matdes.2010.02.008.

4. Mustapa, I. R., Shanks, R. A., \& Kong, I. (2013). Poly (lactic acid)-hemp-nanosilica hybrid composites: thermo mechanical, thermal behavior and morphological properties. International 
Journal of Advanced Science and Engineering Technology, 3(1), 192-199.

5. Maheswari, C. U., Reddy, K. O., Muzenda, E., \& Shukla, M. (2012). Effect of surface treatment on performance of tamarind fiber-epoxy composites. In International Conference on Innovations in Chemical Engineering and Medical Sciences (pp. 16-19). Dubai: Planetary Scientific Research Centre.

6. Asuke, F., Abdulwahab, M., Aigbodion, V. S., Fayomi, O. S. I., $\&$ Aponbiede, O. (2014). Effect of load on the wear behavior of polypropylene /carbonized bone ash particulate composite. Egyptian Journal of Basic and Applied Sciences, 1(1), 67-70. http://dx.doi.org/10.1016/j.ejbas.2014.02.002.

7. Ridzuan, M. J. M., Majid, M. S. A., Afendi, M., Azduwin, K., Amin, N. A. M., Zahri, J. M., \& Gibson, A. G. (2016). Moisture absorption and mechanical degradation of hybrid Pennisetum purpureum/glass-epoxy composites. Composite Structures, 141, 110-116. http://dx.doi.org/10.1016/j.compstruct.2016.01.030.

8. Saba, N., Tahir, P., \& Jawaid, M. (2014). A review on potentiality of nano filler/natural fiber filled polymer hybrid composites. Polymers, 6(8), 2247-2273. http://dx.doi.org/10.3390/ polym6082247.

9. Sathishkumar, T., Naveen, J., \& Satheeshkumar, S. (2014). Hybrid fiber reinforced polymer composites - a review. Journal of Reinforced Plastics and Composites, 33(5), 454-471. http:// dx.doi.org/10.1177/0731684413516393.

10. Kuzmin, K. L., Timoshkin, I. A., Gutnikov, S. I., Zhukovskaya, E. S., Lipatov, Y. V., \& Lazoryak, B. I. (2017). Effect of silane/nano-silica on the mechanical properties of basalt fiber reinforced epoxy composites. Composite Interfaces, 24(1), 13-34. http://dx.doi.org/10.1080/09276440.2016.1182408.

11. Ioannidou, O., \& Zabaniotou, A. (2007). Agricultural residues as precursors for activated carbon production-A review. Renewable \& Sustainable Energy Reviews, 11(9), 1966-2005. http://dx.doi.org/10.1016/j.rser.2006.03.013.

12. Sen, A. K., \& Kumar, S. (2010). Coir-fiber-based fire retardant nano filler for epoxy composites. Journal of Thermal Analysis and Calorimetry, 101(1), 265-271. http://dx.doi.org/10.1007/ s10973-009-0637-8.

13. Jonoobi, M., Khazaeian, A., Tahir, P. M., Azry, S. S., \& Oksman, K. (2011). Characteristics of cellulose nanofibers isolated from rubberwood and empty fruit bunches of oil palm using chemo-mechanical process. Cellulose (London, England), 18(4), 1085-1095. http://dx.doi.org/10.1007/s10570-011-9546-7.

14. Wayan, S. I., Kade, S. I. G. A., \& Arnis, K. (2014). Mechanical properties of rice husks fiber reinforced polyester composites. International Journal of Materials, Mechanics and Manufacturing, 2(2), 165-168. http://dx.doi.org/10.7763/IJMMM.2014.V2.121.

15. Khalil, H. P. S. A., Fizree, H. M., Jawaid, M., \& Alattas, O. S. (2011). Preparation and characterization of nano structured materials from oil palm ash-A bioagricultural waste from oil palm mill. BioResources, 6(4), 4537-4546.

16. Agunsoye, J. O., \& Aigbodion, V. S. (2013). Bagasse filled recycled polyethylene biocomposites: morphological and mechanical properties study. Results in Physics, 3, 187-194. http://dx.doi.org/10.1016/j.rinp.2013.09.003.

17. Saba, N., Jawaid, M., Alothman, O. Y., \& Paridah, M. T. (2016). A review on dynamic mechanical properties of natural fibre reinforced polymer composites. Construction \& Building Materials, 106, 149-159. http://dx.doi.org/10.1016/j. conbuildmat.2015.12.075.

18. Saba, N., Jawaid, M., Alothman, O. Y., Paridah, M. T., \& Hassan, A. (2016). Recent advances in epoxy resin, natural fiber-reinforced epoxy composites and their applications. Journal of Reinforced Plastics and Composites, 35(6), 447470. http://dx.doi.org/10.1177/0731684415618459.

19. Faria, K. C. P., Gurgel, R. F., \& Holanda, J. N. F. (2012). Recycling of sugarcane bagasse ash waste in the production of clay bricks. Journal of Environmental Management, 101,
7-12. http://dx.doi.org/10.1016/j.jenvman.2012.01.032. PMid:22387325

20. Asi, O. (2009). Mechanical properties of glass-fiber reinforced epoxy composites filled with $\mathrm{Al}_{2} \mathrm{O}_{3}$ particles. Journal of Reinforced Plastics and Composites, 28(23), 2861-2867. http:// dx.doi.org/10.1177/0731684408093975.

21. Ibrahim, M. S., Sapuan, S. M., \& Faieza, A. A. (2012). Mechanical and thermal properties of composites from unsaturated polyester filled with oil palm ash. Journal of Mechanical Engineering Science, 2, 133-147. http://dx.doi. org/10.15282/jmes.2.2012.1.0012.

22. Hassan, S. B., Oghenevweta, E. J., \& Aigbodion, V. S. (2012). Potentials of maize stalk ash as reinforcement in polyester composites. Journal of Minerals \& Materials Characterization \& Engineering, 11(4), 445-459. http://dx.doi.org/10.4236/ jmmce.2012.114032.

23. Li, X., Guan, Z., Li, Z., \& Liu, L. (2014). A new stress-based multi-scale failure criterion of composites and its validation in open hole tension tests. Chinese Journal of Aeronautics, 27(6), 1430-1441. http://dx.doi.org/10.1016/j.cja.2014.10.009.

24. Kumar, K. N., Prasanth, M., Krishna, V., \& Rao, D. S. (2013). Experimental investigation on mechanical properties of coal ash reinforced glass fiber polymer matrix composites. International Journal of Emerging Technology and Advanced Engineering, 3(8), 250-258.

25. Shan, Y., \& Liao, K. (2001). Environmental fatigue of unidirectional glass-carbon fiber reinforced hybrid composite. Composites. Part B, Engineering, 32(4), 355-363. http://dx.doi. org/10.1016/S1359-8368(01)00014-2.

26. Tsotsis, T. K., Keller, S., Lee, K., Bardis, J., \& Bish, J. (2001). Aging of polymeric composite specimens for 5000 hours at elevated pressure and temperature. Composites Science and Technology, 61(1), 75-86. http://dx.doi.org/10.1016/S02663538(00)00196-2.

27. Xie, J., Yin, P., Shi, W., Hu, M., Wang, J., Zhou, X., Han, J., Cao, S., Han, L., \& Yao, Y. (2016). Corrosion mechanism of e-glass of chemical resistance glass fiber in acid environment. Journal of Wuhan University of Technology-Mater Science Editor, 31(4), 872-876. http://dx.doi.org/10.1007/s11595-0161461-1.

28. Prakash, S., Kumar, V. S. S., \& Sangaiah, M. (2016). Evaluation of mechanical properties on banana/ bagasse based natural fiber hybrid composite. In 6th International \& 27th All India Manufacturing Technology, Design and Research Conference (pp. 658-662). India: College of Engineering Pune.

29. Wei, B., Song, S., \& Cao, H. (2011). Strengthening of basalt fibers with nano- $\mathrm{SiO}_{2}$-epoxy composite coating. Materials \& Design, 32(8-9), 4180-4186. http://dx.doi.org/10.1016/j. matdes.2011.04.041.

30. Yudhanto, A., Watanabe, N., Iwahori, Y., \& Hoshi, H. (2012). The effects of stitch orientation on the tensile and open hole tension properties of carbon/epoxy plain weave laminates. Materials \& Design, 35, 563-571. http://dx.doi.org/10.1016/j. matdes.2011.09.013.

31. Das, B., Tucker, B. D., \& Watson, J. C. (1991). Acid corrosion analysis of fibre glass. Journal of Materials Science, 26(24), 6606-6612. http://dx.doi.org/10.1007/BF02402652.

32. Prakash, S., Prathab, M., Dhanashekar, M., \& Kumar, V. S. S. (2018). Open hole tensile behaviour of nano fillers ( $\mathrm{SiC} \&$ Banana) in CNSL/epoxy resin reinforeced with basalt fiber. Materials Today Proceedings, 5(2), 8631-8637. http://dx.doi. org/10.1016/j.matpr.2017.11.562.

Received: Mar. 12, 2019

Revised: July 03, 2019

Accepted: July 12, 2019 